\title{
Interpersonal Agency as Predictor of the Within-Patient Alliance Effects on Depression Severity
}

\section{Penedo, Juan Martin Gomez}

2020-04

Penedo , J M G , Babl , A , Krieger , T , Heinonen , E , Flueckiger , C \& Holtforth , M G 2020

, ' Interpersonal Agency as Predictor of the Within-Patient Alliance Effects on Depression

Severity ' , Journal of Consulting and Clinical Psychology , vol. 88 , no. 4 , pp. 338-349 . https://doi.org/10.1037/ccp0

http://hdl.handle.net/10138/321334

https://doi.org/10.1037/ccp0000475

unspecified

acceptedVersion

Downloaded from Helda, University of Helsinki institutional repository.

This is an electronic reprint of the original article.

This reprint may differ from the original in pagination and typographic detail.

Please cite the original version. 
INTERPERSONAL PROBLEMS AND ALLIANCE WITHIN-PATIENT EFFECTS

(c) 2019, American Psychological Association. This paper is not the copy of record and may not exactly replicate the final, authoritative version of the article. Please do not copy or cite without authors' permission. The final article will be available, upon publication, via its DOI: $10.1037 /$ ccp0000475

\section{Interpersonal Agency as Predictor of the Within-Patient Alliance Effects on Depression} Severity

Juan Martín Gómez Penedo ${ }^{1 *}$, Anna Babl ${ }^{1}$, Tobias Krieger ${ }^{1}$, Erkki Heinonen ${ }^{2,3}$, Christoph Flückiger $^{4}$, Martin grosse Holtforth ${ }^{1,5}$

${ }^{1}$ University of Bern, ${ }^{2}$ University of Helsinki, ${ }^{3}$ National Institute for Health and Welfare, Finland, ${ }^{4}$ University of Zurich, ${ }^{5}$ University Hospital Insel

*Corresponding autor: Juan Martín Gómez Penedo. Address: Secretaria de Investigaciones, Facultad de Psicología, Universidad de Buenos Aires, 2353 Lavalle St., Ciudad de Buenos Aires, Argentina. E-mail: jmgomezpenedo@gmail.com. Phone: +54 91165257053. 


\begin{abstract}
Aim. Several studies have reported significant within-patient effects of the therapeutic alliance on outcome. However, it remains uncertain whether there are specific patient groups for whom an improved alliance might be particularly beneficial. The relational nature of the alliance makes patients' interpersonal problems a promising candidate for examining such differential effects. This study aims to analyze (i) between- and within-patient effects of the alliance on depression severity, (ii) the effects of patients' baseline interpersonal problems on the within-patient alliance-outcome association, and (iii) whether within-patient effects of the alliance remain significant when adjusting for patients' initial interpersonal problems. Methods. A sample of 141 patients with depression and undergoing outpatient psychotherapy completed the Inventory of Interpersonal Problems at baseline as well as a brief version of the Working Alliance Inventory and the Well-Being Index (as a proxy of depression severity) session-by-session. Results. Multilevel models revealed both significant between- and withinpatient effects of the alliance on improvements in depression severity. Patients' problems relating to agency had a significant effect on the within-patient effect of alliance, with more submissive patients benefiting more from an improved therapeutic alliance. Finally, the between- and within-patient effects of the alliance remained significant when adjusting for the patients' agentic interpersonal problems and treatment condition. Conclusions. The results provide evidence on which types of patients would particularly benefit from an improved therapeutic alliance. For patients suffering from low interpersonal agency and reporting problems with submissiveness, an enhanced alliance during the therapy process might improve treatment outcome.
\end{abstract}

Keywords: Alliance; Within-Patient Effects; Interpersonal Problems; Depression; Cognitive Therapy 
INTERPERSONAL PROBLEMS AND ALLIANCE WITHIN-PATIENT EFFECTS

\section{Public Health Significance Statements}

Higher overall levels as well as improvements during psychotherapy in the quality of the patient-rated therapeutic alliance are associated with better treatment outcomes of depression. Patients suffering from interpersonal problems related to being too submissive benefit most from an improved therapeutic alliance during therapy. These results might have important clinical implications for how to responsively adapt interventions to patients' salient characteristics and thereby improve treatment outcomes. 
INTERPERSONAL PROBLEMS AND ALLIANCE WITHIN-PATIENT EFFECTS

\section{Interpersonal agency as predictor of the within-patient alliance effects on depression}

\section{severity}

The therapeutic alliance is the most agreed upon common factor of psychotherapy, an element shared by most if not all psychotherapeutic approaches (Norcross \& Lambert, 2018). Not only has the development and nurturing of the alliance been recognized as a legitimate therapeutic process (Castonguay, Eubanks, Goldfried, Muran, \& Lutz, 2015), but it has also received the most empirical attention in psychotherapy process research (Flückiger, Del Re, Wampold, \& Horvath, 2018). This is in part due to several meta-analyses showing alliance to be one of the most robust predictors of psychotherapy outcome (Flückiger et al., 2018; Horvath, Del Re, Flückiger, \& Symonds, 2011) across a wide range of patient diagnoses and different treatment types (Flückiger, Del Re, Wampold, Symonds, \& Horvath, 2012). Greater alliance scores have consistently been associated with greater therapeutic improvement. However, the quality of the therapeutic alliance may influence therapy outcome in at least two ways. First, patients with generally higher levels of alliance relative to other patients may achieve greater outcomes (between-patient effects); second, for a given patient, an improved alliance over time may lead to greater therapeutic gains (within-patient effects). Yet previous research has mainly focused only on between-patient differences in the alliance as a predictor of therapy outcome (Falkenström, Granström, \& Holmqvist, 2013). Albeit, such analyses do not necessarily mean that improving the alliance will improve treatment outcome for a specific patient.

In the last decade, there has been a general call to explore within-patient effects of alliance on therapy outcome (Falkenström et al., 2013; Zilcha-Mano \& Errázuriz, 2015). Most of the studies answering this query have found both between- and within-patient effects, showing that not only a generally high level of alliance over the course of treatment matters for better outcomes, but also the improvement of the alliance during the therapeutic process (Coyne, Constantino, Westra, \& Antony, 2019; Falkenström et al., 2013; Falkenström, Finkel, 
Sandell, Rubel, \& Holmqvist, 2017; Hoffart, Øktedalen, Langkaas, \& Wampold, 2013; Rubel, Zilcha-Mano, Feils-Klaus, \& Lutz, 2018; Zilcha-Mano \& Errázuriz, 2015; Zilcha-Mano et al., 2016). Since this research focus has developed only recently, it is yet unclear whether these within-patient effects are homogenous among patients, or if differential effects based on specific patient characteristics exist. The question is whether certain patients benefit more or less from improvements in the therapeutic alliance. Previous research has found that for patients with affective or anxiety disorders, the within-patient effects of the alliance might be affected by several patient baseline variables such as symptom severity (Lorenzo-Luaces, DeRubeis, \& Webb, 2014; Rubel, Zilcha-Mano, Giesemann, Prinz, \& Lutz, 2019; ZilchaMano \& Errázuriz, 2015), well-being, personality style, emotional and psychological functioning (Rubel et al., 2019), number of prior depressive episodes (Lorenzo-Luaces et al., 2014), and the presence or absence of personality disorders (Falkenström et al., 2013).

Besides these baseline predictors, the intrinsic relational nature of the alliance suggests patients' interpersonal problems as promising candidates to moderate the effects of alliance on therapy outcome (Gómez Penedo, Zilcha-Mano, \& Roussos, 2019). Patients with certain interpersonal difficulties might benefit substantially from an improved alliance, whereas for patients with other interpersonal issues such change may not be as decisive (Constantino, Coyne et al., 2017). Interpersonal problems may be characterized as relational difficulties grounded in behaviors that are manifested either too little or too much in social interactions. Based on interpersonal theory, eight subtypes of interpersonal problems have been differentiated (i.e., domineering, intrusive, overly nurturant, exploitable, submissive, socially avoidant, cold, and vindictive) which are distributed within a circumplex model (Horowitz, 2004). These eight subtypes reflect varying degrees of problematic behaviors on the two underlying dimensions of interpersonal issues: problems related to communion (describing behavior ranging from detached/hostile on the one side to dependent/overly nurturant on the 


\section{INTERPERSONAL PROBLEMS AND ALLIANCE WITHIN-PATIENT EFFECTS}

other) and problems related to agency (ranging from submissive/nonassertive on the one hand to dominant behavior on the other).

Previous studies have found patients' interpersonal problems to be associated with both the therapeutic alliance (Constantino \& Smith-Hansen, 2008; Dinger, Strack, Sachsse, \& Schauenburg, 2009; grosse Holtforth et al., 2014; Johansen, Melle, Iversen, \& Hestad, 2013; Renner et al., 2012) and treatment outcome (Dammann et al., 2016; Dinger, Strack, Leichsenring, \& Henning, 2007; Dinger, Zilcha-Mano, Mccarthy, Barrett, \& Barber, 2013; Quilty, Mainland, Mcbride \& Bagby; 2013). Also, interpersonal problems may significantly moderate the effect of different treatments, suggesting some therapy models may fit certain interpersonal problems particularly well (Gómez Penedo, Constantino, Coyne, Bernecker, \& Smith-Hansen, 2018; Gómez Penedo, Constantino, Coyne, Westra, \& Antony, 2017; Newman, Jacobson, Erickson, \& Fisher, 2017). Furthermore, some studies have found interpersonal problems to moderate the effects of both early therapeutic alliance and early alliance negotiation on outcome (Gómez Penedo, Zilcha-Mano, \& Roussos, 2019; ZilchaMano \& Errázuriz, 2015). Yet others have shown changes in interpersonal problems during treatment to mediate the within-patient effect of alliance on clinical improvement (Anderson et al., 2018; Coyne et al., 2019).

More specifically to the interest of this study, Rubel et al. (2019), using machine learning methods, found general interpersonal distress together with ten other baseline predictors (out of 95 possible) to moderate the within-patient alliance effect on outcome. Providing more nuance to these findings, Zilcha-Mano, Muran, Eubanks, Safran, and Winston (2018) identified distinct interpersonal problems at baseline that moderated the within-patient effect of alliance on outcome using random forest methods. For patients who described themselves as overly cold or were described as markedly low on intrusiveness by their therapists, a strengthening of the alliance predicted better outcome. Besides these contributions, to the best of our knowledge, there is no previous study that disaggregates 


\section{INTERPERSONAL PROBLEMS AND ALLIANCE WITHIN-PATIENT EFFECTS}

within- and between-patient effects of alliance on outcome and analyzes how the two dimensions of interpersonal problems (i.e., agency and communion problems) are related to within-patient effects of alliance on outcome. These interpersonal indices are particularly relevant because they synthesize information about several interpersonal problems into two main dimensions that reflect two underlying motivational dimensions or basic human needs of agency and communion (Horowitz, 2004; Sullivan, 1953). According to this model, the varied frustrations of one or both of these two basic motives are considered to form the basis of essentially all interpersonal suffering. Furthermore, a recent study found that dimensional models of interpersonal problems significantly and consistently outperform categorical models (Wendt et al., 2019). For these reasons, the inclusion of patients' interpersonal problem dimensions might provide further precision and parsimony to the differential prediction of outcome by the therapeutic alliance (Gómez Penedo, Morgade, Alalu, \& Roussos, 2018).

Therefore, the aim of this study is to disentangle within- and between patient effects of alliance on outcome and to analyze how the two main dimensions of agentic and communal interpersonal problems at baseline predict the within-patient alliance effect. Furthermore, as the alliance might still be important for treatment outcome regardless of the patients' interpersonal problems, we are also interested in testing if both the between- and withinpatient effects of alliance on outcome remain significant when adjusting for patients' interpersonal problems. Accordingly, our research hypotheses are as follows: i) between- and within-patient effects of alliance will predict therapy outcome during acute psychotherapy for depression (hypothesis \#1), ii) the interpersonal problem dimensions (i.e., agency and communion) will predict differential within-patient effects of the alliance on treatment outcome (hypothesis \#2), and iii) the between- and within-patient effects of alliance on outcome will remain significant when controlling for agency and communion (hypothesis \#3). From a conceptual point of view, testing hypothesis \#1 of the study will provide us with 


\section{INTERPERSONAL PROBLEMS AND ALLIANCE WITHIN-PATIENT EFFECTS}

information regarding the clinical relevance of alliance levels and variations during treatment. Testing hypothesis \#2 will inform us whether interpersonal problems can help identify patients for whom an improvement in the therapeutic alliance over the course of treatment would be particularly beneficial. Finally, testing hypothesis \#3 will show us if the alliance variations and levels during treatment are clinically relevant for treatment regardless of patients' interpersonal problems. Analyzing these three hypotheses could provide meaningful information for clinical practice and treatment optimization.

\section{Methods}

\section{Participants}

The sample in the present study consisted of 141 patients who were treated in a psychotherapeutic outpatient clinic of a Swiss University ${ }^{1}$. Patients were randomly assigned to a maximum of 22 weekly sessions of either exposure-based cognitive therapy (EBCT; $n=$ 70) or cognitive behavioral therapy (CBT; $n=71)$. To be eligible, patients had to be at least 18 years old and meet diagnostic criteria for major depression. Diagnoses were established using the Structured Clinical Interview for DSM-IV-R (First, Spitzer, Gibbon, \& Williams, 1997) conducted by trained graduate students and research assistants. Before the intake interview, patients gave their written informed consent. In the EBCT condition, twelve cases dropped out during therapy, while in the CBT condition eight cases did not complete the treatment. However, it is worth noting that all the cases who completed the outcome measure and had at least completed the baseline assessment were included in the analysis of the study.

On average, patients were 40.8 years of age $(S D=11.4)$. The majority of participants were female $(55.3 \%)$, currently not in a romantic relationship (i. e., single, separated, divorced or widowed; 59.4\%), and had previously received psychotherapy (59.4\%). Most of the

\footnotetext{
${ }^{1}$ Note that the sample of the parental trial included 149 cases who were randomized to one of the two treatments (grosse Holtforth et al., 2019). However, due to our analytic strategy, we were only able to include all the participants who completed the outcome variable at least once over the course of treatment $(n=143)$. Of these cases, two patients withdrew from the trial and requested their data not to be used. These facts explain the final study sample size $(n=141)$.
} 
INTERPERSONAL PROBLEMS AND ALLIANCE WITHIN-PATIENT EFFECTS

participants had at least either completed a professional training $(40.4 \%)$ or a university degree (39.7\%). All the patients who participated in the study had a main diagnosis of Major Depressive Disorder (MDD), with $73 \%$ of the patients presenting a diagnosis of recurrent depression (39.5\% mild, $47.4 \%$ moderate, and $13.1 \%$ severe), and $27 \%$ presenting a singleepisode depression (35.0\% mild, $44.7 \%$ moderate, and $20.3 \%$ severe). In total, $34.8 \%$ of the sample presented with comorbid anxiety disorders. Additionally, 27.7\% had a comorbid personality disorder. Specifically, $14.2 \%$ of the patients had a comorbid diagnosis of Depressive Personality Disorder.

Patients were treated by 25 master level psychologists who either had completed their postgraduate training in psychotherapy or were currently enrolled in the program. All therapists were Caucasian and $92 \%$ were female with an average age of 31.4 years $(S D=5.1)$. One of the therapists had already finished the postgraduate therapy training, while 10 were in the third or fourth year of the training and 14 in the first or second year. As part of their postgraduate training, all the therapists had received courses on CBT for depression. For this trial, the therapist received also trainings both in CBT and EBCT for depression, as well as particular trainings in emotion-focused techniques, activity scheduling, assertiveness training, and mindfulness techniques (for more details see grosse Holtforth et al., 2019). Furthermore, during the study all the therapists had biweekly video-based supervision meetings in small groups, conducted by experts from the respective treatment condition (either CBT or EBCT$\mathrm{R})$.

Therapists saw on average 5.8 patients within the trial $(S D=2.8)$. All therapists delivered both treatments and were assigned to an equivalent number of patients in each treatment condition.

\section{Materials}

Therapeutic Alliance. The quality of the therapeutic alliance was assessed using a German adapted version of the Working Alliance Inventory - client form (WAI; Horvath \& 
INTERPERSONAL PROBLEMS AND ALLIANCE WITHIN-PATIENT EFFECTS

Greenberg, 1989). This brief version of the WAI integrated by three items (one per subscale of the WAI) was created using the one item of each subscale that showed the greatest itemsubscale correlation. For the "goal subscale" the selected item was "[The therapist] and I were working towards mutually agreed upon goals". For the "task subscale" the item was "I believe the way we were working with my problem was correct". And for the "bond subscale" the item was "I feel that [the therapist] appreciated me". The items were rated on a 5-point Likert scale ranging from 1 (never) to 5 (always). As we wanted to measure alliance after each session, we selected this three-item version of the WAI to reduce the burden on patients. For a total score, the three items are averaged. In the current sample, the total score of the brief version of the WAI showed a moderate to large correlation $(r=.69, p<.001)$ with the therapeutic relationship subscale of the Bern Post-Session Report - patient form (BPSR/P; Flückiger, Regli, Zwahlen, Hostettler, \& Caspar, 2010). Using a function developed by Zimmermann (2015) to estimate multilevel reliability, we found that in this sample the WAI had a between-patient standardized alpha of .85 and a within-patient standardized alpha of 67.

Interpersonal Problems. We used the German adaptation of the short form of the Inventory of Interpersonal Problems (IIP-32; Horowitz, Aiden, Wiggins, \& Pincus, 2000), a widely used questionnaire for the self-assessment of the type and level of distress associated with interpersonal phenomena and situations. The IIP-32 consists of 32 items rated on a 5point Likert scale from 0 (not at all) to 4 (extremely) corresponding to different distressing interpersonal excesses or inhibitions (Horowitz et al., 2000). The items of the IIP-32 are distributed over eight subscales within the Interpersonal Circumplex (Horowitz et al., 2004): domineering, intrusive, overly nurturant, exploitable, submissive, socially avoidant, cold, and vindictive. Based on the subscales it is possible to calculate the two orthogonal interpersonal dimensions of communion (from detached/hostile behavior on the negative pole to dependent/overly nurturant behavior on the positive pole) and agency (from submissive 


\section{INTERPERSONAL PROBLEMS AND ALLIANCE WITHIN-PATIENT EFFECTS}

behavior on the negative pole to dominant behavior on the positive pole). The theoretical range for the interpersonal dimensions is -2.42 to 2.42 . The German version of the IIP-32 has shown good psychometric properties (Thomas, Brahler, \& Strauss, 2011). In the current sample, the total score of the IIP at baseline showed a Cronbach's alpha of .84 .

Depression severity. In this study, we used the German version of the World Health Organization Well-Being Index (WHO-5; WHO, 1998). The WHO-5 is a distressquestionnaire that was originally created to measure subjective psychological well-being using 5 items rated on a 6-point Likert scale ranging from 0 (at no time) to 5 (all of the time). The WHO-5 has shown robust psychometric properties and has been found to have adequate validity in screening for depression (Henkel et al., 2003) and in measuring outcome in clinical trials (Topp, Østergaard, Søndergaard, \& Bech, 2015). Furthermore, empirical research showed that WHO-5 is a valid measure for assessing depression severity (Krieger et al., 2014). Thus, in this study we used the WHO-5 as a proxy of depression severity, with higher WHO-5 scores representing lower severity and lower scores implying greater severity. Although in the parental trial there were other measurements of depression severity such as the German adaptation of the Beck Depression Inventory-II (BDI-II; Hautzinger, Keller, \& Kühner, 2006), the WHO-5 was the only measure assessed session-by-session (see grosse Holtforth et al., 2019). That was our main reason for selecting WHO-5 as our outcome measure. In the sample of the current study, the WHO-5 presented a moderate to large correlation with the BDI-II $(r=-.63)$ across the four time points when both instruments were assessed. In the current sample, the between-patient standardized alpha of the WHO-5 was .90 and the within-patient standardized alpha was .94 .

\section{Procedure}

All the participants of the study provided informed consent before being enrolled in the trial. Before the treatments started, all patients completed the IIP-32 as part of a larger questionnaire package at baseline. Furthermore, they completed the WHO-5 before each 
INTERPERSONAL PROBLEMS AND ALLIANCE WITHIN-PATIENT EFFECTS

therapy session and the WAI after each therapy session. The therapists did not receive any feedback regarding patients' ratings on the WAI or the WHO-5. The local ethics committee approved the procedures of the study. For further details on the procedures of the study, see grosse Holtforth and colleagues (2019).

\section{Analytical strategy}

To characterize the sample interpersonally at baseline, we used the circular statistics and the structural summary methods (Wright, Pincus, Conroy, \& Hilsenroth, 2009), using the $R$ package circumplex (Girard, Zimmermann, \& Wright, 2018). The circular statistics method is an analytic approach based on patient's angular projection on the circumplex (Wright, Pincus, Conroy, \& Hilsenroth, 2009). It provides an average angular displacement (i.e., circular mean) for the sample, a 95\% confidence interval for this angular displacement $\left(\mathrm{CI}_{95}\right)$, and the deviation around sample's average angular displacement (i.e., circular variance). The structural summary method plots patients' data on a sinusoidal curve allowing to identify the sample's interpersonal profile based on the four meaningful parameters of angular displacement, i.e., elevation, amplitude, and goodness-of-fit (Wright, Pincus, Conroy, \& Hilsenroth, 2009). As recommended in previous literature, we used standardized $z$-score transformations based on normative data for these analyses (Zilcha-Mano et al., 2015).

To test the main hypotheses of the study, we used hierarchical linear models (HLM; Raudenbush \& Bryk, 2002). HLM deals with the dependency of data due to repeated measures, providing a robust strategy to handle missing data within patients. These models mimic an intent-to-treat approach, allowing to include all participants with at least one measurement point in a given outcome variable into the analyses. In this study, the multiple assessment times of the WHO-5 served as outcome variable, nested within patients that were in turn nested within therapists. Thus, all the analyzes were conducted using three-level HLM models (Level 1: within-patient effects, Level 2: between-patient effects, Level 3: betweentherapist effects). First, for comparison purposes, we ran a three-level fully unconditional 
INTERPERSONAL PROBLEMS AND ALLIANCE WITHIN-PATIENT EFFECTS

model and a three-level unconditional time-as-only predictor model with the dependent variable being WHO-5 scores in both cases. In the fully unconditional model, we did not include any predictor to explain WHO-5 variance (see Equation 1 of the Supplemental material), while in the time-as-only predictor models we incorporated time (defined as session number and centered at post-treatment) as a level-1 predictor (see Equation 2 of the Supplemental material).

Second, we ran three-level hybrid random effect models (HREM) with the WHO-5 scores as the dependent variable (Falkenström et al., 2017). These models allow disaggregating between- and within-patients effects of the alliance on therapy outcome by including the time-varying quality of the alliance as a level-1 predictor, person-mean centered (estimating the within-patient effect of the alliance) and the overall level of alliance during the whole treatment as a level-2 predictor of the intercept grand-mean centered (estimating the between-patient effect of the alliance) (Curran \& Bauer, 2011). In the literature concerning these methods, there is an important debate regarding how to deal with time effects (see e.g., Falkenström et al., 2017). When both the time-varying predictor and the outcome variable present a trend over time, some authors recommended controlling for time effects (i.e., detrending; Curran \& Bauer, 2011; Hoffman \& Stawski, 2009). However, this procedure could limit the effect of unobserved confounders that are associated with both variable trends explaining the putative association between them (Falkenström et al., 2017). However, more recent studies have indicated that this will imply a very restrictive and conservative procedure that is not recommended when the natural evolution of the targeted variables will be consistent with their time trends (Falkenström et al., 2017; Wang \& Maxwell, 2015).

For this study, we followed the recommendation of Falkenström et al. (2017) considering a synthesis of these two positions. For testing hypothesis \#1, as a first step, we ran the HREM without controlling for time effect (i.e., not detrending; see Equation 3 of the Supplemental material). In the case of significant effects, as a second step, we ran the same 


\section{INTERPERSONAL PROBLEMS AND ALLIANCE WITHIN-PATIENT EFFECTS}

models controlling for the time effect (i.e., detrending) to see if the results were maintained. As suggested by Wang and Maxwell (2015) and to control for the time effect, we included time (defined as session number) as a level-1 predictor (see Equation 4 of the Supplemental material). If after detrending the results remained significant, this would strengthen the possibility of causal inferences based on the findings (Falkenström et al., 2017). To adjust for treatment condition effects, we also included treatment as a level-2 predictor in these models $(\mathrm{EBCT}=-0.5, \mathrm{CBT}=0.5)$

After this, we ran three-level HREM not detrending and including interpersonal dimensions (i.e., agency and communion) as level-2 predictors of the within-patient alliance effects. As written in the introduction, we decided to draw on a dimensional interpersonal model based on recent evidence demonstrating that dimensional interpersonal models outperformed the categorical ones (i.e., dividing the sample into differential interpersonal profiles) in terms of model fit, predictive validity and robustness (Wendt et al., 2019). For these analyses, we ran two main effects models including the interpersonal level-2 predictors separately, i.e., either agency or communion (see Equation 5 in the Supplemental material), one main effects model including both agency and communion as level-2 predictors (see Equation 6 in the Supplemental material), and an interactive effects model including the interactive effect of agency by communion as a level-2 predictor (see Equation 7 in the Supplemental material). Using model comparison tests, we selected the most parsimonious model (i.e., the model explaining the largest proportion of variance with the least number of parameters; Raudenbush \& Bryk, 2002) as the final model to explain within-patient alliance effects as a function of patient's interpersonal problems. These models allowed us to test if patients' interpersonal problems predict the within-patient alliance effects on outcome (hypothesis \#2) and also if the within-patient alliance effects remained significant when adjusting for effects of interpersonal-problem dimensions (hypothesis \#3). All the HLM analyses were run on the HLM software using robust standard errors (Raudenbush, Bryk, \& 
INTERPERSONAL PROBLEMS AND ALLIANCE WITHIN-PATIENT EFFECTS

Congdon, 2011). To model level-1 residuals, we used an unstructured (UN) covariance structure.

\section{Results}

\section{Sample descriptives}

In Table 1, we present the descriptive statistics of the main variables of the study at baseline. We also present independent sample $t$-tests and Bayesian independent-sample tests based on 2,000 iterations, to compare the baseline scores between the two treatment conditions. Results showed no evidence of differences between the two treatment conditions at baseline. In Table SM1 in the Supplemental material, we presented the correlations at baseline among the variables of the study.

When characterizing the sample's overall interpersonal profile, the circular statistics revealed a circular angular mean of 256.30 for the sample (Circular variance $=33.20, \mathrm{CI}_{95}$ $[250.91,261.68])$, consistent with a submissive and slightly hostile interpersonal profile. The structural summary method showed an angular displacement of 252.50 ( $\mathrm{CI}_{95}$ [236.01, 268.45]) also consistent with a submissive and slightly hostile interpersonal profile (see Figure SM1 in the Supplemental material). The elevation of the profile reached 0.50. The amplitude of the profile (0.43) gives evidence for a distinct interpersonal profile and the $R^{2}$ of .87 indicates a very good profile fit (cf. Wright, Pincus, Conroy, \& Elliot, 2009).

\section{Preliminary analyses}

The results of all models conducted are summarized in Table 2. The fully unconditional model showed that on average the participants presented a WHO-5 value of 2.02, $\gamma_{000}=2.02, S E=0.06, \mathrm{CI}_{95}[1.90,2.14], t(24)=33.26, p<.001$. Furthermore, the unconditional time-as-only predictor model showed that there was a significant effect of time on the WHO-5, $\gamma_{100}=0.05, S E=0.01, \mathrm{CI}_{95}[0.03,0.07], t(2668)=10.29, p<.001$. On average, patients increased 0.05 units on the WHO-5 from session to session. The inclusion of time, 
i.e., session number, significantly increased the variance explained by the model, $\chi^{2}(1)=$ $440.53, p<.001^{2}$.

\section{Alliance effects on outcome (hypothesis \#1)}

Compared with the fully unconditional model, the results of the hybrid model that included the alliance as a predictor demonstrated a significant improvement in the model fit, $\chi^{2}(5)=337.48, p<.001$. In this model, we found a significant between-patient effect of the quality of the therapeutic alliance, measured with the WAI, on the WHO-5 scores during treatment, $\gamma_{010}=0.50, S E=0.13, \mathrm{CI}_{95}[0.25,0.75], t(114)=3.91, p<.001$. A one-unit greater alliance level during treatment was associated with an increase of 0.50 units on the WHO-5 score (i.e., with a lower depression severity) during therapy. Furthermore, the model shows significant within-patient effects of the alliance on WHO-5 scores, $\gamma_{100}=0.57, S E=0.06$, $\mathrm{CI}_{95}[0.45,0.69], t(2666)=9.40, p<.001$. A one-unit fluctuation of patients' alliance score from their individual alliance mean was associated with a fluctuation of 0.57 units on the WHO-5 score. When running the same models with detrending, we still found significant between-patient alliance effects, $\gamma_{010}=0.49, S E=0.13, \mathrm{CI}_{95}[0.24,0.74], t(114)=3.68, p<.001$, and within-patient alliance effects, $\gamma_{100}=0.30, S E=0.06, \mathrm{CI}_{95}[0.18,0.42], t(2665)=5.26, p<$ $.001^{3}$

\section{The dimensions of interpersonal problems as predictors of the within-patient alliance}

\section{effects (hypothesis \#2)}

\footnotetext{
${ }^{2}$ An unconditional time-as-only predictor model with WAI as the dependent variable, showed also a significant session-by-session increase of WAI during treatment, $\gamma_{100}=0.02, S E=0.001, \mathrm{CI}_{95}[0.018,0.022], t(2668)=13.91$, $p<.001$. On average patients tend to increase 0.02 units of WAI every session. This model represents a significant improvement of model's fit compared to a fully unconditional model, $\chi^{2}(1)=320.88, p<.001$.

${ }^{3}$ To replicate these findings we ran the same models but using the therapeutic relationship (TR) subscale from the Bern Post-Session Report (Flückiger et al., 2010) instead of the WAI. The results of the models not detrending showed significant between-patients effects of TR, $\gamma_{010}=0.58, S E=0.14, \mathrm{CI}_{95}[0.31,0.85], t(114)=$ $4.17, p<.001$, and within-patient effects of TR, $\gamma_{100}=0.34, S E=0.06, \mathrm{CI}_{95}[0.22,0.46], t(2666)=5.89, p<.001$. The inclusion of this effects significantly improved the model fit from fully unconditional model, $\chi^{2}(5)=193.52$, $p<.001$. Finally, we ran a model which included the between- and within-patient effects of both WAI and TR on outcome, to see if the within-effects of each measure remained significant when controlling for the other variables. The results showed significant within-patient effects of WAI on outcome when controlling for TR, $\gamma_{100}=0.53, S E=0.05, \mathrm{CI}_{95}[0.44,0.63], t(2665)=11.04, p<.001$, but not significant within-patient effects of TR when controlling for WAI effects, $\gamma_{200}=0.03, S E=0.05, \mathrm{CI}_{95}[-0.07,0.13], t(2665)=0.56, p=.58$.
} 
INTERPERSONAL PROBLEMS AND ALLIANCE WITHIN-PATIENT EFFECTS

The main effects model with agency as the only level-2 predictor of the within-patient effect of alliance significantly improved the model fit of the HREM disaggregating betweenand within- alliance effects, $\chi^{2}(2)=6.25, p<.05$. The model which included communion as the only level-2 predictor did not significantly improve the model fit of the alliance main effects model, $\chi^{2}(2)=1.13, p>.50$. Furthermore, the model including both agency and communion as level-2 predictors did not significantly improve the variance explained by the model with agency as the only predictor, $\chi^{2}(2)=1.90, p>.50$. Finally, the model including agency, communion, and an interactive term of agency by communion also did not significantly improve the model fit when compared to the agency as only predictor model, $\chi^{2}(4)=4.75, p=.31$. Based on these results, we decided to select the main effects model with agency as the only predictor as the final model for the analysis.

The results of this model showed a significant effect of agency on the within-patient effect of alliance on outcome, $\gamma_{130}=-0.17, S E=0.08, \mathrm{CI}_{95}[-0.33,-0.01], t(2665)=-2.28, p=$ .02. A one-unit greater score of agency at baseline was related with a reduction of 0.17 units in the association between a one-unit fluctuation in the alliance and the WHO-5 scores. Thus, in submissive patients (i.e., with lower agency scores at baseline), there was a greater association between fluctuations of the therapeutic alliance and outcome. When running the same model but detrending (i.e., controlling for the time effect), the effect of agency on the within-patient effect of alliance remained significant, $\gamma_{130}=-0.16, S E=0.08, \mathrm{CI}_{95}[-0.32$, 0.003], $t(2664)=-2.10, p=.04$. Furthermore, when controlling for patients' overall interpersonal distress (i.e., including as a level-2 predictor both of the intercept and of the within-patient alliance effect), the agency effect on the within-patient alliance effect was also still significant, both in the models not detrending, $\gamma_{130}=-0.17, S E=0.08, \mathrm{CI}_{95}[0.33,-0.01]$, 
$t(2664)=-2.23, p=.03$, and in the models detrending, $\gamma_{130}=-0.17, S E=0.08, \mathrm{CI}_{95}[-0.33,-$ $0.01], t(2663)=-2.09, p=.04 .^{4}$

\section{Alliance effects when controlling for interpersonal problems dimensions (hypothesis \#3)}

To test if the alliance still presented significant between- and within-patient effects on outcome when controlling for patient's interpersonal dimensions, we also drew on the final main effect model with agency as the only interpersonal predictor. This model showed that when adjusting for interpersonal agency, there were still significant between-patient effects of alliance on WHO-5 scores, $\gamma_{010}=0.50, S E=0.13, \mathrm{CI}_{95}[0.25,0.75], t(113)=3.99, p<.001$. Furthermore, the within-patient effect of alliance also remained significant when controlling for agency, $\gamma_{100}=0.57, S E=0.06, \mathrm{CI}_{95}[0.45,0.69], t(2664)=9.42, p<.001$. When detrending the model, we observed a similar pattern of results for between-patient effects, $\gamma_{010}=0.48, S E=$ $0.13, \mathrm{CI}_{95}[0.23,0.73], t(113)=3.74, p<.001$, and within-patient effects, $\gamma_{100}=0.31, S E=0.06$, $\mathrm{CI}_{95}[0.19,0.43], t(2664)=5.35, p<.001$.

\section{Regions of significance for the agency effect}

In order to further understand the effect of agency on the within-patient alliance effect, we calculated regions of significance as a follow-up analysis, using Preacher, Curran, and Bauer's (2006) online calculator for HLM two-way interactions based on the slopes as outcomes model. This analysis allowed us to identify at what conditional values of the agency dimension the within-patient effect of alliance starts being significant, identifying two

\footnotetext{
${ }^{4}$ To try to further replicate these findings we ran the same final model (with agency as the only predictor) but using again the therapeutic relationship (TR) subscale from the BPSR. This model did not show a significant improvement in the model fit, $\chi^{2}(2)=3.55, p=.17$. Furthermore, although the agency effect on the withinpatient TR effect on outcome was in the same direction as in the original model (i.e., submissive patients benefiting more from the within-patient alliance effects), the effect was not significant, $\gamma_{130}=-0.13, S E=0.09$, $\mathrm{CI}_{95}[-0.31,0.05], t(2665)=-1.32, p=.19$. To understand this, it may be worthwhile to note that the three items of the BPSR (i.e.," "The therapist and I understand each other", "Today I felt well in the relationship with the therapist", and "I think the therapist is really interested in my well-being") mainly capture the classical bond dimension of alliance while not measuring the agreement of patient and therapist on the tasks and goals of therapy. Considering that the agency dimension concerns problems with the power dynamics between two individuals, it plausibly relates more to the effects of agreement/disagreements in the alliance than the bond dimension, which in turn would theoretically be more associated to the communion interpersonal dimension (Horowitz et al., 2017). This might explain the failure to replicate the agency effects when predicting the withinpatient effects of TR on outcome.
} 
INTERPERSONAL PROBLEMS AND ALLIANCE WITHIN-PATIENT EFFECTS

boundaries that define a region for the significant effect. The result of this analysis determined a score of 1.15 on agency for the lower boundary and a score of 23.38 for the upper boundary, indicating the simple slopes of alliance to be significant when they were outside that region. As the theoretical range of the agency dimension is -2.42 to 2.42 , this means that only in participants with a baseline level of agency below 1.15, the within-patient effect of alliance was significant.

These results further support hypothesis \#2 and \#3 of the study. On the one hand, as presented in Figure 1 (derived from the region of significance analysis), the within-patient alliance effect on outcome increased as a function of lower baseline levels of agency. Consistent with hypothesis \#2, patients with submissive interpersonal problems (i.e., low agency) seemed to benefit more from positive changes in the alliance during therapy. Furthermore, consistent with hypothesis \#3, the region of the significant effect captures a wide range of patients, showing that the within-patient effects are still relevant above and beyond patients' agentic interpersonal problems.

\section{Discussion}

This study aimed to disaggregate within- and between patient effects of alliance on outcome and to analyze if the two main dimensions of baseline interpersonal problems (agency and communion) predict the within-patient effect of alliance on outcome. Additionally, in this paper we sought to examine whether both between- and within-patient effects of alliance remain significant when controlling for patients' meaningful interpersonal problem dimensions.

The results of the study showed significant between- and within-patient effects of the alliance, thus supporting hypothesis \#1 of the study. These findings are supported by previous studies showing both between- and within-patient effects of alliance on outcome (Coyne et al., 2019; Falkenström et al., 2013, 2017; Rubel et al., 2018, Schwartz, Hilbert, Schlegl, Diedrich, \& Voderholzer, 2018; Zilcha-Mano \& Errázuriz, 2015). This means that not only is 


\section{INTERPERSONAL PROBLEMS AND ALLIANCE WITHIN-PATIENT EFFECTS}

a higher level of alliance in treatment important, but so is the within-patient improvement of the alliance throughout treatment. From a clinical perspective, these findings support the general aim to strengthen the quality of the alliance during therapy. Additionally, our results suggest that it is important to pay particular attention to potential strains in the relationship that might undermine the quality of the relationship during treatment (Eubanks, Muran, \& Safran, 2018). In this respect, the results might imply that it will be particularly relevant to focus on training therapists' skills, especially interpersonal skills (Constantino, Boswell, Coyne, Kraus, \& Castonguay, 2017; Heinonen \& Nissen-Lie, 2019; Wampold \& Imel, 2015), to enhance treatment outcome (Safran, Muran, \& Eubanks-Carter, 2011; Eubanks et al., 2018).

The results of the current analyses also suggest that patients differ regarding the effects of alliance on outcome, based on their interpersonal problems (hypothesis \#2). Submissive patients (i.e., with lower scores on the agency dimension), seem to benefit more from an increase in alliance during treatment. Previous studies showed that reductions in patients' in-session submissive behaviors towards their therapist were associated with better outcomes (Constantino, Romano, Coyne, Westra, \& Antony, 2018), especially in patients who presented with interpersonal problems of low agency (Gómez Penedo, Constantino et al., 2019). For those patients, an increase in alliance (i.e., patient-therapist collaboration) might help to reduce their in-session submissive behaviors with the therapist and facilitate a more active participation in commitment to therapy. Future research might need to empirically explore the mechanisms underlying the effects of interpersonal problems on the allianceoutcome link.

Furthermore, in clinical practice submissive patients might have a hard time expressing their interpersonal concerns to the therapist (Horowitz, Gómez Penedo, Roussos, \& Silberschatz, 2017), instead taking an overly compliant stance towards the treatment and the professional (Muran, Segal, Samstag, \& Crawford, 1994). Thus, in the case they develop 


\section{INTERPERSONAL PROBLEMS AND ALLIANCE WITHIN-PATIENT EFFECTS}

negative feelings towards the therapist (e.g., anger or frustration), they might not disclose their feelings explicitly. If such issues are not recognized and addressed in time by the therapist, this might represent a risk for treatment success that could ultimately lead to early dropout, lack of improvement, or deterioration. Therefore, the ability of the therapist to both provide affection and validate the patient's opinions and needs via a strong alliance could represent a key process for such patients and facilitate corrective interpersonal experiences that might help reduce symptom severity and burden (Constantino \& Westra, 2012, Gómez Penedo, Zilcha-Mano \& Roussos, 2019; Macaulay, Angus, Khatta, Westra, \& Ip, 2017).

Moreover, for patients with interpersonal problems relating to submissiveness (i.e., low agency), an increase in the alliance during treatment might facilitate changes regarding their interpersonal difficulties, in turn, leading to better outcome. This idea is consistent with other interpersonal theories stating that depression is maintained by a hostile-submissive interpersonal style, the changing of which will lead to symptomatic improvement (Coyne, 1976; Hames, Hagan, \& Joiner, 2013; Joiner, 2000). The interpersonal profile of this study sample, obtained via the circular statistics and structural summary methods, is consistent with this hypothesis of a predominantly hostile-submissive style in depressive patients. Additionally, empirical findings support the notion that an increase in agency during treatment for depression is associated with better long-term outcome (Altenstein-Yamanaka, Zimmermann, Krieger, Dörig, \& grosse Holtforth, 2017) and that the within-patient effects of alliance on outcome are mediated by changes in overall interpersonal problems (Coyne et al., 2019). A greater increase of alliance in patients with submissive interpersonal difficulties might help modify these patients' interpersonal patterns, which is hypothesized to be a main mechanism of change in several treatments for depression (Hames et al., 2013), such as Cognitive Behavioral Analysis System of Psychotherapy (McCullough, 2003) and Interpersonal Psychotherapy (Weissman, Markowitz, \& Klerman, 2000). These findings may have implications for clinical practice and therapist training. The results suggest that 


\section{INTERPERSONAL PROBLEMS AND ALLIANCE WITHIN-PATIENT EFFECTS}

therapists would benefit from measuring patients' interpersonal problems at baseline and paying particular attention to the therapeutic alliance in those patients who present low levels of agency. This knowledge could be incorporated into clinical trainings, providing trainees with an if, then approach to adapt technical interventions and treatments based on patients' interpersonal markers (Constantino, Boswell, Bernecker, \& Castonguay, 2013; Gómez Penedo et al., 2017; Heinonen \& Pos, 2019).

Furthermore, this study also provides evidence of significant between- and withinpatient effects of alliance on outcome when controlling for interpersonal problem dimensions (hypothesis \#3). This means that the alliance accounts for an important part of outcome variance, above and beyond the patients' interpersonal problems. Thus, regardless of the patients' interpersonal problems, improving the therapeutic alliance can generally be considered beneficial in depression therapy. The follow-up analyses that established regions of significance for the within-patient alliance effects depending on the patient's interpersonal agency provide further support and detail to this hypothesis. They show that the within-patient alliance effects increase as a function of the patient's level of submissive interpersonal problems, which are relevant to a wide range of depressive patients.

Although this study represents a step forward in understanding the within-patient effects of the alliance via multilevel models, it is worthwhile to note other perspectives and

methods that might be relevant to fully understand the implications of these findings. For instance, analyzing in-session rupture-repair episodes on the alliance also provided evidence of within-patient effects of alliance on outcome (Eubanks et al., 2018). Future studies might benefit from exploring how patients' interpersonal problems may have an effect on the association between alliance rupture-resolutions with outcome (Gómez Penedo, Zilcha-Mano, \& Roussos, 2019).

This study has several limitations that might be addressed in future research and that call for interpreting the results with caution. Alliance was measured with a very brief version 


\section{INTERPERSONAL PROBLEMS AND ALLIANCE WITHIN-PATIENT EFFECTS}

of the WAI, based on the three items that presented the greatest item-subscale correlations. The psychometric properties of this version of the WAI have not been examined previously, although in the current sample the instrument presented evidence of external validity, based on their associations with the therapeutic relationship subscale of the BPSR. In this context, it is worth noting that there is a growing trend in the literature to use brief versions or even single-item scales to measure process or outcome variables in order to reduce the burden on the patients who complete the instruments and thereby better enable gathering and analysis of session-by-session data (see Fisher \& Boswell, 2016; Rubel et al., 2018). Although the between-patient standardized alpha was good for this version of the WAI, the within-patient alpha was slightly below the acceptable threshold of .70 (Tavakol \& Dennick, 2011). Among others, this comparably low score may be explained by the small amount of items of the scale (Streiner et al., 1993). However, the low longitudinal reliability could also have a meaningful clinical explanation, i.e., being an indication of rupture-repair patterns between-sessions (Safran et al., 2011) that might increase the within-patient error observed in the WAI. Furthermore, the elevated scores of the alliance during treatment evidence a ceiling effect (Paap, Schepers, \& Dijkstra, 2019), which is very common when studying the therapeutic alliance (e.g. Falkenström et al., 2013; Owen \& Hilsenroth, 2011) and might imply a loss of statistical power in the mixed models applied. Future research will need to replicate these findings using a more robust alliance instrument, with evidence of greater longitudinal reliability, and with a greater item-per-scale ratio that would increase the range of the variance and limit the possibility of ceiling effects (Kivlighan \& Shaughnessy, 1995). Additionally, the measures of interpersonal problems, alliance, and outcome were selfreported by the patients. This might imply a risk of shared-variance bias due to common sources (Podsakoff, MacKenzie, Lee, \& Podsakoff, 2003). In addition, as self-reported interpersonal problems describe patients' self-perception of their relational difficulties, it is important to acknowledge that the perception of a patient's interpersonal problems by 
INTERPERSONAL PROBLEMS AND ALLIANCE WITHIN-PATIENT EFFECTS

significant others may differ from self-reports (Altenstein-Yamanaka et al., 2017). Future research might benefit from analyzing the effects of interpersonal problems on the allianceoutcome association incorporating alternative sources (e.g., patient interpersonal problems as evaluated by significant others, alliance as rated by the therapist, patient interpersonal impacts on the therapist, etc.). With regard to the generalizability of our results, it should be considered that although this mirrors the broader clinical reality, most therapists where female and about one quarter of the patients presented with comorbid personality disorders. Furthermore, most of the patients had been involved in a previous psychotherapy. These features of the sample raise concerns regarding generalizability of the findings of this study, calling for future replication of its results in different samples. Lastly, patients in the sample of the present study had a primary diagnosis of an MDD. It will be interesting to see whether results of the present study can be corroborated in patients with other diagnoses.

Beyond these limitations, this study provides evidence regarding patients for whom improvements in the alliance would be particularly important based on their interpersonal problems. Especially in patients with low interpersonal agency reporting more submissive interpersonal problems, enhancing the alliance during the therapeutic process might improve treatment outcome. 
INTERPERSONAL PROBLEMS AND ALLIANCE WITHIN-PATIENT EFFECTS

\section{References}

Altenstein-Yamanaka, D., Zimmermann, J., Krieger, T., Dörig, N., \& grosse Holtforth, M. (2017). Self-reported interpersonal problems and impact messages as perceived by significant others are differentially associated with the process and outcome of depression therapy. Journal of Counseling Psychology, 64, 410-423. https://doi.org/10.1037/cou0000221

Anderson, T., McClintock, A. S., McCarrick, S. S., Heckman, T. G., Heckman, B. D., Markowitz, J. C., \& Sutton, M. (2018). Working alliance, interpersonal problems, and depressive symptoms in tele-interpersonal psychotherapy for $\mathrm{HIV}$-infected rural persons: Evidence for indirect effects. Journal of Clinical Psychology, 74, 286-303.

Castonguay, L. G., Eubanks, C. F., Goldfried, M. R., Muran, J. C., \& Lutz, W. (2015). Research on psychotherapy integration: Building on the past, looking to the future. Psychotherapy Research, 25, 365-382.

Constantino, M. J., Boswell, J. F., Bernecker, S. L., \& Castonguay, L. G. (2013). Contextresponsive psychotherapy integration as a framework for a unified clinical science: Conceptual and empirical considerations. Journal of Unified Psychotherapy and Clinical Science, 2, 1-20.

Constantino, M. J., Boswell, J. F., Coyne, A. E., Kraus, D. R., \& Castonguay, L. G. (2017). Who works for whom and why? Integrating therapist effects analysis into psychotherapy outcome and process research. In L. G. Castonguay \& C. E. Hill (Eds.), How and why are some therapists better than others?: Understanding therapist effects (pp. 55-68). Washington, DC, US: American Psychological Association.

Constantino, M. J., Coyne, A. E., Luukko, E. K., Newkirk, K., Bernecker, S. L., Ravitz, P., \& McBride, C. (2017). Therapeutic alliance, subsequent change, and moderators of the alliance-outcome association in interpersonal psychotherapy for depression. Psychotherapy, 54, 125. 


\section{INTERPERSONAL PROBLEMS AND ALLIANCE WITHIN-PATIENT EFFECTS}

Constantino, M. J., Romano, F. M., Coyne, A. E., Westra, H. A., \& Antony, M. M. (2018). Client interpersonal impacts as mediators of long-term outcome in cognitivebehavioral therapy integrated with motivational interviewing for generalized anxiety disorder. Psychotherapy Research, 28, 861-872.

Constantino, M. J., \& Smith-Hansen, L. (2008). Patient interpersonal factors and the therapeutic alliance in two treatments for bulimia nervosa. Psychotherapy Research, 18, 683-698. https://doi.org/10.1080/10503300802183702

Constantino, M. J., \& Westra, H. A. (2012). An expectancy-based ap- proach to facilitating corrective experiences in psychotherapy. In L. G. Castonguay \& C. E. Hill (Eds.), Transformation in psychotherapy: Corrective experiences across cognitive, behavioral, humanistic, and psychodynamic approaches (pp. 121-139). Washington, DC: American Psychological Association. http://dx.doi.org/10.1037/13747-008

Coyne, J. C. (1976). Toward an interactional description of depression. Psychiatry, 39, 28-40.

Coyne, A. E., Constantino, M. J., Westra, H. A., \& Antony, M. M. (2019). Interpersonal change as a mediator of the within- and between-patient alliance-outcome association in two treatments for generalized anxiety disorder. Journal of Consulting and Clinical Psychology, 87, 472-483. doi:10.1037/ccp0000394

Curran, P. J., \& Bauer, D. J. (2011). The disaggregation of within-person and between-person effects in longitudinal models of change. Annual Review of Psychology, 62, 583-619. https://doi.org/10.1146/annurev.psych.093008.100356

Dammann, G., Riemenschneider, A., Walter, M., Sollberger, D., Kuchenhoff, J., Gundel, H., ... Gremaud-Heitz, D. J. (2016). Impact of interpersonal problems in borderline personality disorder inpatients on treatment outcome and psychopathology. Psychopathology, 49, 172-180. https://doi.org/10.1159/000446661

Dinger, U., Strack, M., Leichsenring, F., \& Henning, S. (2007). Influences of patients' and therapists' interpersonal problems and therapeutic alliance on outcome in 
INTERPERSONAL PROBLEMS AND ALLIANCE WITHIN-PATIENT EFFECTS

psychotherapy. Psychotherapy Research, 17, 148-159. doi:

$10.1080 / 10503300600865393$

Dinger, U., Strack, M., Sachsse, T., \& Schauenburg, H. (2009). Therapists' attachment, patients' interpersonal problems and alliance development over time in inpatient psychotherapy. Psychotherapy Theory, Research, Practice, Training, 46, 277-290. https://doi.org/10.1037/a0016913

Dinger, U., Zilcha-Mano, S., Mccarthy, K. S., Barrett, M. S., \& Barber, J. P. (2013). Interpersonal problems as predictors of alliance, symptomatic improvement and premature termination in treatment of depression. Journal of Affective Disorders, 151, 800-803. https://doi.org/10.1016/j.jad.2013.07.003

Eubanks, C. F., Muran, J. C., \& Safran, J. D. (2018). Alliance rupture repair: A meta-analysis. Psychotherapy, 55, 508-519.

Falkenström, F., Finkel, S., Sandell, R., Rubel, J. A., \& Holmqvist, R. (2017). Dynamic models of individual change in psychotherapy process research. Journal of Consulting and Clinical Psychology, 85, 537-549. https://doi.org/10.1037/ccp0000203

Falkenström, F., Granström, F., \& Holmqvist, R. (2013). Therapeutic alliance predicts symptomatic improvement session by session. Journal of counseling psychology, 60 , 317-328.

First, M. B., Spitzer, R. L., Gibbon, M., \& Williams, J. B. (1997). User's guide for the Structured clinical interview for DSM-IV axis I disorders SCID-I: clinician version. American Psychiatric Pub.

Fisher, A. J., \& Boswell, J. F. (2016). Enhancing the personalization of psychotherapy with dynamic assessment and modeling. Assessment, 23, 496-506.

Flückiger, C., Del Re, A. C., Wampold, B. E., \& Horvath, A. O. (2018). The alliance in adult psychotherapy: A meta-Analytic Synthesis. Psychotherapy, 55, 316-340. 
INTERPERSONAL PROBLEMS AND ALLIANCE WITHIN-PATIENT EFFECTS

Flückiger, C., Del Re, A. C., Wampold, B. E., Symonds, D., \& Horvath, A. O. (2012). How central is the alliance in psychotherapy? A multilevel longitudinal meta-analysis. Journal of counseling psychology, 59, 10-17.

Flückiger, C., Regli, D., Zwahlen, D., Hostettler, S., \& Caspar, F. (2010). Der Berner Patienten-und Therapeutenstundenbogen 2000. Zeitschrift für Klinische Psychologie und Psychotherapie, 39, 71-79.

Girard, J., Zimmermann, J., \& Wright, A. (2018). circumplex: Analysis and Visualization of Circular Data. $\mathrm{R}$ package version 0.2.1. https://CRAN.Rproject.org/package $=$ circumplex

Gomez Penedo, J. M., Constantino, M. J., Coyne, A. E., Bernecker, S. L., \& Smith-Hansen, L. (2018). Patient baseline interpersonal problems as moderators of outcome in two psychotherapies for bulimia nervosa. Psychotherapy Research. Advance online publication. https://doi.org/10.1080/10503307.2018.1425931

Gómez Penedo, J. M., Constantino, M. J., Coyne, A. E., Romano, F., Westra, H. A., \& Antony, M. M. (2019). Baseline client interpersonal agency moderates the indirect effect of treatment on long-term worry in variants of CBT for Generalized Anxiety Disorder. Behavior Therapy. Advance online publication. doi:10.1016/j.beth.2019.01.007

Gomez Penedo, J. M., Constantino, M. J., Coyne, A. E., Westra, H. A., \& Antony, M. M. (2017). Markers for context-responsiveness: Client baseline interpersonal problems moderate the efficacy of two psychotherapies for generalized anxiety disorder. Journal of Consulting and Clinical Psychology, 85, 1000-1011. doi:10.1037/ccp0000233

Gómez Penedo, J. M., Morgade, F., Alalu, N. \& Roussos, A. J. (2018). El rol de los procesos interpersonales en la psicoterapia: efectos sobre el tratamiento y recursos de adaptación clínica [The role of interpersonal processes in psychotherapy: their effects on treatment and how to use it as resources of clinical adaptation]. In: H. Fernández 
INTERPERSONAL PROBLEMS AND ALLIANCE WITHIN-PATIENT EFFECTS

Álvarez, M. Maristany, C. Bregman, \& A. Pérez. Enciclopedia Argentina de Salud Mental.

Gómez Penedo, J.M., Zilcha-Mano, S., \& Roussos, A. (2019). Interpersonal profiles in emotional disorders predict the importance of alliance negotiation for early treatment outcome. Journal of Consulting and Clinical Psychology. Advance online publication. doi:10.1037/ccp0000417

grosse Holtforth, M., Altenstein, D., Krieger, T., Flückiger, C., Wright, A. G., \& Caspar, F. (2014). Interpersonal differentiation within depression diagnosis: Relating interpersonal subgroups to symptom load and the quality of the early therapeutic alliance. Psychotherapy Research, 24, 429-441.

grosse Holtforth, M., Krieger, T., Zimmermann, J., Dörig, N., Meisch, L., Hayes, A. M., ... Zimmermann, J. (2019). A randomized-controlled trial of cognitive - behavioral therapy for depression with integrated techniques from emotion-focused and exposure therapies. Psychotherapy Research, 29, 30-44. doi:10.1080/10503307.2017.1397796

Hames, J. L., Hagan, C. R., \& Joiner, T. E. (2013). Interpersonal processes in depression. Annual Review of Clinical Psychology, 9, 355-377. doi:10.1146/annurev-clinpsy050212-185553

Hautzinger, M., Keller, F., \& Kühner, C. (2006). Das Beck Depressionsinventar II. Deutsche Bearbeitung und Handbuch zum BDI II [The Beck Depression Inventory II. German Adaptation and Manual of the BDI II]. Frankfurt a. M.: Harcourt Test Services.

Heinonen, E., \& Nissen-Lie, H. A. (2019). The professional and personal characteristics of effective psychotherapists: A systematic review. Psychotherapy Research. doi: $10.1080 / 10503307.2019 .1620366$

Heinonen, E., \& Pos, A. E. (2019). The role of pre-treatment interpersonal problems for emotional processing and long-term outcome in emotion-focused therapy. 
INTERPERSONAL PROBLEMS AND ALLIANCE WITHIN-PATIENT EFFECTS

Psychotherapy Research. Advance online publication. doi:10.1080/10503307.2019.1630778

Henkel, V., Mergl, R., Kohnen, R., Maier, W., Möller, H., \& Hegerl, U. (2003). The WHO-5 wellbeing index performed the best in screening for depression in primary care. Evidence Based Medicine, 8, 155.

Hoffart, A., Øktedalen, T., Langkaas, T. F., \& Wampold, B. E. (2013). Alliance and outcome in varying imagery procedures for PTSD: A study of within-person processes. Journal of Counseling Psychology, 60, 471-482. doi:10.1037/a0033604

Hoffman, L., \& Stawski, R. S. (2009). Persons as contexts: Evaluating between-person and within-person effects in longitudinal analysis. Research in Human Development, 6, 97-120.

Horowitz, L. M. (2004). Interpersonal Foundations of Psychopathology. Washington, DC: American Psychological Association.

Horowitz, L. M., Alden, L. E., Wiggins, J. S., \& Pincus, A. L. (2000). IIP: Inventory of Interpersonal Problems manual. San Antonio, TX: Psychological Corporation.

Horowitz, L., Gómez Penedo, J.M., Roussos, A., \& Silberschatz, G. (2017, July). Agency the overlooked dimension in assessing a therapeutic relationship. Paper presented at the 20th Annual Meeting of the Society for Interpersonal Theory and Research. Pittsburgh, USA.

Horvath, A. O., Del Re, A. C., Flückiger, C., \& Symonds, D. (2011). Alliance in individual psychotherapy. Psychotherapy, 48, 9-16.

Horvath, A. O. \& Greenberg, L. S. (1989). Development and validation of the Working Alliance Inventory. Journal of counseling psychology, 36, 223.

Johansen, R., Melle, I., Iversen, V. C., \& Hestad, K. (2013). Personality traits, interpersonal problems and therapeutic alliance in early schizophrenia spectrum disorders. Comprehensive Psychiatry, 54, 1169-1176. doi:10.1016/j.comppsych.2013.05.016 
INTERPERSONAL PROBLEMS AND ALLIANCE WITHIN-PATIENT EFFECTS

Joiner, T. E. (2000). Depression's vicious scree: Self-propagating and erosive processes in depression chronicity. Clinical Psychology: Science and Practice, 7, 203-218.

Kivlighan, D. M., \& Shaughnessy, P. (1995). Analysis of the development of the working alliance using Hierarchical Linear Modeling. Journal of Counseling Psychology, 42, $338-349$.

Krieger, T., Zimmermann, J., Huffziger, S., Ubl, B., Diener, C., Kuehner, C., \& Holtforth, M. G. (2014). Measuring depression with a well-being index: further evidence for the validity of the WHO Well-Being Index (WHO-5) as a measure of the severity of depression. Journal of affective disorders, 156, 240-244.

Lorenzo-Luaces, L., DeRubeis, R. J., \& Webb, C. A. (2014). Client characteristics as moderators of the relation between the therapeutic alliance and outcome in cognitive therapy for depression. Journal of Consulting and Clinical Psychology, 82, 368-373. https://doi.org/10.1037/a0035994

Macaulay, C., Angus, L., Khattra, J., Westra, H., \& Ip, J. (2017). Client retrospective accounts of corrective experiences in motivational interviewing integrated with cognitive behavioral therapy for generalized anxiety disorder. Journal of Clinical Psychology, 73, 168-181.

McCullough, J. P. (2003). Treatment for chronic depression using Cognitive Behavioral Analysis System of Psychotherapy (CBASP). Journal of Clinical Psychology / in Session, 59, 833-846. https://doi.org/10.1002/jclp.10176

Muran, J. C., Segal, Z. V, Samstag, L. W., \& Crawford, C. E. (1994). Patient Pretreatment Interpersonal Problems and Therapeutic Alliance in Short-Term Cognitive Therapy. Journal of Consulting and Clinical Psychology, 62, 185-190.

Newman, M. G., Jacobson, N. C., Erickson, T., \& Fisher, A. J. (2017). Interpersonal problems predict differential response to cognitive versus behavioral treatment in a randomized controlled trial. Behavior Therapy, 48, 56-68. doi:10.1016/j.beth.2016.05.005 
INTERPERSONAL PROBLEMS AND ALLIANCE WITHIN-PATIENT EFFECTS

Norcross, J. C., \& Lambert, M. J. (2018). Psychotherapy relationships that work III. Psychotherapy, 55, 303-315.

Owen, J., \& Hilsenroth, M. J. (2011). Interaction between alliance and technique in predicting patient outcome during psychodynamic psychotherapy. The Journal of Nervous and Mental Disease, 199, 384-389. https://doi.org/10.1097/NMD.0b013e31821cd28a

Paap, D., Schepers, M., \& Dijkstra, P. U. (2019). Reducing ceiling effects in the Working Alliance Inventory-Rehabilitation Dutch Version. Disability and Rehabilitation. Advance online publication. https://doi.org/10.1080/09638288.2018.1563833

Podsakoff, P. M., MacKenzie, S. B., Lee, J.-Y., \& Podsakoff, N. P. (2003). Common method biases in behavioral research: a critical review of the literature and recommended remedies. Journal of Applied Psychology, 88, 879-903. doi:10.1037/00219010.88.5.879

Preacher, K. J., Curran, P. J., \& Bauer, D. J. (2006). Computational tools for probing interaction effects in multiple linear regression, multilevel modeling, and latent curve analysis. Journal of Educational and Behavioral Statistics, 31, 437-448.

Quilty, L. C., Mainland, B. J., Mcbride, C., \& Bagby, R. M. (2013). Interpersonal problems and impacts: Further evidence for the role of interpersonal functioning in treatment outcome in major depressive disorder. Journal of Affective Disorders, 150, 393-400. http://doi.org/10.1016/j.jad.2013.04.030

Raudenbush, S. W. \& Bryk, A. S. (2002). Hierarchical linear models: Applications and data analysis methods (2nd ed.). Thousand Oaks, CA: Sage.

Raudenbush, S. W., Bryk, A. S., \& Congdon, R. (2011). HLM 7 for Windows [Computer software]. Lincolnwood, IL: Scientific Software International.

Renner, F., Jarrett, R. B., Vittengl, J. R., Barrett, M. S., Anna, L., \& Thase, M. E. (2012). Interpersonal problems as predictors of therapeutic alliance and symptom 
INTERPERSONAL PROBLEMS AND ALLIANCE WITHIN-PATIENT EFFECTS

improvement in cognitive therapy for depression. Journal of Affective Disorders, 138, 458-467. http://doi.org/10.1016/j.jad.2011.12.044

Rubel, J. A., Zilcha-Mano, S., Feils-Klaus, V., \& Lutz, W. (2018). Session-to-session effects of alliance ruptures in outpatient CBT: Within-and between-patient associations. Journal of Consulting and Clinical Psychology, 86, 354.

Rubel, J. A., Zilcha-Mano, S., Giesemann, J., Prinz, J., \& Lutz, W. (2019). Predicting personalized process-outcome associations in psychotherapy using machine learning approaches - A demonstration. Psychotherapy Research. Advance online publication. https://doi.org/10.1080/10503307.2019.1597994

Safran, J. D., Muran, J. C., \& Eubanks-Carter, C. (2011). Repairing alliance ruptures. Psychotherapy, 48, 80-87. http://doi.org/10.1037/a0022140

Schwartz, C., Hilbert, S., Schlegl, S., Diedrich, A., \& Voderholzer, U. (2018). Common change factors and mediation of the alliance - outcome link during treatment of depression. Journal of Consulting and Clinical Psychology, 86, 584-592.

Streiner, D. L. (1993). A checklist for evaluating the usefulness of rating scales. Canadian Journal of Psychiatry, 38, 140-148.

Sullivan, H. D. (1953). The interpersonal theory of psychiatry. New York, NY: Routledge.

Tavakol, M., \& Dennick, R. (2011). Making sense of Cronbach's alpha. International Journal of Medical Education, 2, 53-55.

Thomas, A., Brahler, E., \& Strauss, B. (2011). IIP-32 Entwicklung, Validierung und Normierung einer Kurzform des Inventars zur Erfassung interpersonaler Probleme. Diagnostica, 57, 68-83.

Topp, C. W., Østergaard, S. D., Søndergaard, S., \& Bech, P. (2015). The WHO-5 Well-Being Index: a systematic review of the literature. Psychotherapy and Psychosomatics, 84, 167-176. 
INTERPERSONAL PROBLEMS AND ALLIANCE WITHIN-PATIENT EFFECTS

Wampold, B. E. \& Imel, Z. E. (2015). The great psychotherapy debate: The evidence for what makes psychotherapy work (2nd ed.). New York, NY: Routledge.

Wang, L. P., \& Maxwell, S. E. (2015). On disaggregating between-person and within-person effects with longitudinal data using multilevel models. Psychological Methods, 20, $63-83$.

Weissman, M.M., Markowitz, J.C., \& Klerman, G.L. (2000). Comprehensive guide to interpersonal psychotherapy. New York: Basic Books.

Wendt, L.P., Wright, A.G.C., Pilkonis, P.A., Nolte, T., Fonagy, P., Montague, P.R., Benecke, C., Krieger, T., \& Zimmermann, J. (in press). The latent structure of interpersonal problems: Validity of dimensional, categorical and hybrid models. Journal of Abnormal Psychology.

World Health Organization (1998). Wellbeing measure in primary health care/ The Depcare Project. WHO Regional Office for Europe: Copenhagen.

Wright, A. G. C., Pincus, A. L., Conroy, D. E., \& Elliot, A. J. (2009). The pathoplastic relationship between interpersonal problems and fear of failure. Journal of Personality, 77, 997-1024. https://doi.org/10.1111/j.1467-6494.2009.00572.x

Wright, A. G. C., Pincus, A. L., Conroy, D. E., \& Hilsenroth, M. J. (2009). Integrating methods to optimize circumplex description and comparison of groups. Journal of Personality Assessment, 91, 311-322. https://doi.org/10.1080/00223890902935696

Zilcha-Mano, S., \& Errázuriz, P. (2015). One size does not fit all: Examining heterogeneity and identifying moderators of the alliance-outcome association. Journal of Counseling Psychology, 62, 579-591.

Zilcha-Mano, S., McCarthy, K. S., Dinger, U., Chambless, D. L., Milrod, B. L., Kunik, L., \& Barber, J. P. (2015). Are there subtypes of Panic Disorder? An interpersonal perspective. Journal of Consulting and Clinical Psychology, 83, 938-950. 
INTERPERSONAL PROBLEMS AND ALLIANCE WITHIN-PATIENT EFFECTS

Zilcha-Mano, S., Muran, J. C., Eubanks, C. F., Safran, J. D., \& Winston, A. (2018). Not just a non-specific factor: Moderators of the effect of within-and between-clients alliance on outcome in CBT. Cognitive Therapy and Research, 42, 146-158.

Zilcha-Mano, S., Muran, J. C., Hungr, C., Eubanks, C. F., Safran, J. D., \& Winston, A. (2016). The relationship between alliance and outcome: Analysis of a two-person perspective on alliance and session outcome. Journal of Consulting and Clinical Psychology, 84, 484-496. doi:10.1037/ccp0000058

Zimmermann, J. (2015). R script for estimating four different indices of multilevel reliability. R function version 1.11.

\section{Appendix: Data Transparency}

This paper is a secondary analysis of data derivate from a randomized control trial. So far four studies (besides the main outcome paper) have been conducted based on this same dataset. One of these studies (already published), used correlations to analyze the associations of interpersonal problems and their changes during treatment with (i) process variables (among others the early quality of the alliance during the first five sessions of treatment) and (ii) changes in outcome variables from pre-treatment to post-treatment and from posttreatment to follow-up. It is worthwhile to note that this study did not analyze the allianceoutcome association, disaggregating between- and within-patient effects, nor analyzed how interpersonal problems might predict the within-patient effects of alliance on outcome. Another paper already published based on this dataset analyzed the associations between selfcompassion and depression severity during follow-up period using cross-lagged panel analyses. Furthermore, there are two studies currently under review. One study analyzed the effects of discrepancy between patient implicit and explicit negative self-associations at posttreatment on long-term outcome. The other study created an algorithm based on a Personalized Advantage Index approach, using patient characteristics at baseline to identify which treatment would be the optimal one for the patient. 
Table 1

Mean, standard deviation, and treatment comparison of the targeted variables in the study at baseline.

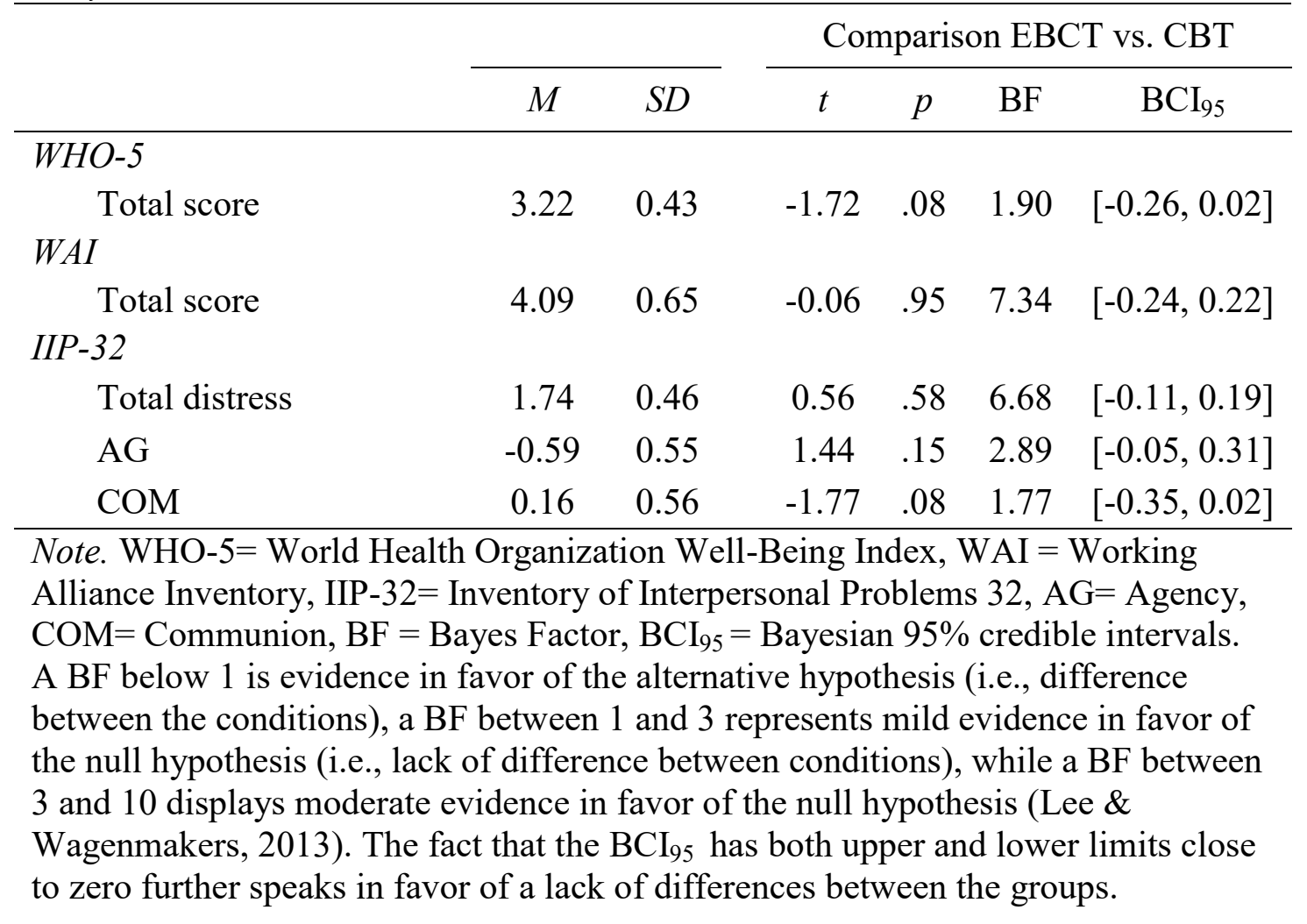


Table 2

Results of the unconditional model, time-as-only predictor model, alliance main effect model, and final conditional effects model with agency as the only predictor of the alliance effect

\begin{tabular}{|c|c|c|c|c|c|c|}
\hline \multirow[b]{2}{*}{ Fixed Model Effects } & \multicolumn{2}{|c|}{ WHO-5 level $\left(\pi_{0 j k}\right)$} & \multicolumn{2}{|c|}{$\begin{array}{c}\text { Alliance within- } \\
\text { patient effect on } \\
\text { WHO-5 scores }\left(\pi_{l j k}\right)\end{array}$} & \multicolumn{2}{|c|}{$\begin{array}{l}\text { WHO-5 rate of } \\
\text { change during } \\
\text { treatment }\left(\pi_{2 j k}\right)\end{array}$} \\
\hline & $\gamma$ & $S E$ & $\gamma$ & $S E$ & $\gamma$ & $S E$ \\
\hline $\begin{array}{l}\text { Fully unconditional } \\
\text { Intercept }\end{array}$ & $2.02 * * *$ & 0.06 & & & & \\
\hline $\begin{array}{l}\text { Time-as-only } \\
\text { predictor } \\
\quad \text { Intercept } \\
\text { Model comparison }\end{array}$ & $2.56 * * *$ & 0.10 & $c^{2}(1)=440$ & $<.001$ & $0.05 * * *$ & 0.004 \\
\hline $\begin{array}{l}\text { Main effects of } \\
\text { alliance } \\
\text { Intercept } \\
\text { Treatment } \\
\text { Alliance level } \\
\text { Model comparison } \\
\end{array}$ & $\begin{array}{c}2.02 * * * \\
-0.05 \\
0.50 * * *\end{array}$ & $\begin{array}{l}0.05 \\
0.13 \\
0.13\end{array}$ & $\begin{array}{r}0.57 * * * \\
0.01 \\
0.39 * * * \\
\chi^{2}(5)=337 .\end{array}$ & $\begin{array}{l}0.06 \\
0.11 \\
0.10 \\
0<.001\end{array}$ & & \\
\hline $\begin{array}{l}\text { Conditional effects of } \\
\text { AG on alliance effects } \\
\text { Intercept } \\
\text { Treatment } \\
\text { Alliance level } \\
\text { AG } \\
\text { Model comparison }\end{array}$ & $\begin{array}{c}2.02 * * * \\
-0.07 \\
0.50 * * * \\
0.13\end{array}$ & $\begin{array}{l}0.05 \\
0.13 \\
0.13 \\
0.09\end{array}$ & $\begin{array}{c}0.29 * * * \\
0.01 \\
0.10 \\
-0.13^{*} \\
\chi^{2}(2)=6.2\end{array}$ & $\begin{array}{l}0.05 \\
0.09 \\
0.11 \\
0.06 \\
<.05\end{array}$ & & \\
\hline $\begin{array}{l}\text { Note. In the reported } \mathrm{n} \\
\text { main effects alliance } \mathrm{n} \\
\text { conditional model with } \\
\text { the main effects allian } \\
\text { Communion; } * * * p<\end{array}$ & $\begin{array}{l}\text { el compa } \\
\text { el were c } \\
\text { ency as } \mathrm{t} \\
\text { nodel. Tr } \\
\text {, } * * p<\end{array}$ & $\begin{array}{l}\text { tests, } \\
\text { ared wi } \\
\text { nly pre } \\
\text { ent }=0 \\
* p<.0\end{array}$ & $\begin{array}{l}\text { th the time- } \\
\text { the fully un } \\
\text { tor of the a } \\
\mathrm{T}=.5, \mathrm{EBC} \\
\dagger p<.10\end{array}$ & $\begin{array}{l}\text { nly pred } \\
\text { ditional } \\
\text { ce effect } \\
-.5 ; \mathrm{AG}^{=}\end{array}$ & $\begin{array}{l}\text { model a } \\
\text { el, while } \\
\text { s compa } \\
\text { ency; CC }\end{array}$ & $\begin{array}{l}\text { the } \\
\text { with } \\
=\end{array}$ \\
\hline
\end{tabular}




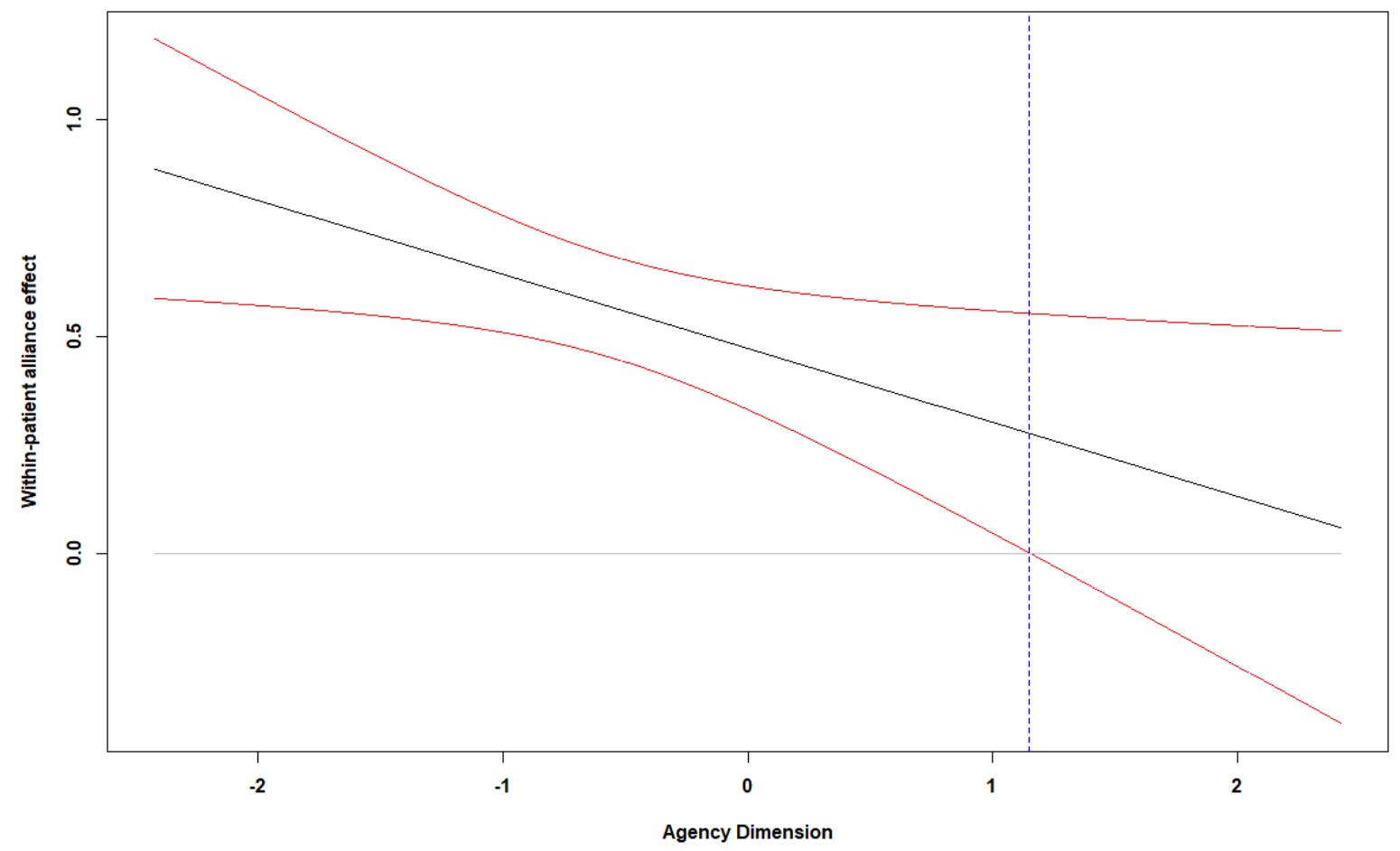

Figure 1. Estimated within-patient effects of alliance on WHO-5 scores during treatment based on conditional values of Agency interpersonal dimension with confidence intervals. 